\title{
RESEARCH ON GEOGRAPHY TEACHING AND TEACHER EDUCATION IN PORTUGAL
}

\author{
ELSA PACHECO
}

Faculty of Arts, University of Porto, Portugal; CITCEM research center, e-mail: elsap@letras.up.pt

\section{CRISTIANA MARTINHA}

Faculty of Arts, University of Porto, Portugal; CITCEM research center, e-mail: cristiana.martinha@gmail.com

\author{
ANTÓNIO COSTA \\ Faculty of Arts, University of Porto, Portugal; CITCEM research center, e-mail: afonso.costa@gmail.com
}

(Received: April 2015; in revised form: June 2015)

\begin{abstract}
This article aims to contribute to the debate on the significance of geographical education as part of the development of a society in which information and communication technologies have made profound changes. It starts with the discussion on how Geography is taught at international scale, and then addresses the intersection between research produced in the reports on the introduction to professional practice and related study plans, concerning the $2^{\text {nd }}$ cycle of the teaching of History and Geography, in force since 2010 in Portugal. Based on the outcomes of the discussion, we will consider the research trends and whether or not they are suited to the latest recommendations on geographical education, in particular the training of Geography teachers, according to the assessed proposals which were submitted following the new law regulating the training of Geography teachers in Portugal. Among the main outcomes, we highlighted the diversity of topics addressed in the internship reports and the growing attention to new technologies in the cycle of studies under analysis, which suggests the adequacy of the future Masters in the Teaching of Geography at the University of Porto (starting in 2015/16) to the European recommendations on these matters.
\end{abstract}

Keywords: Geography teaching, ICT, teacher training 
ROMANIAN REVIEW OF GEOGRAPHICAL EDUCATION, Volume IV, Number 2, August 2015

\section{INTRODUCTION}

The vulgarization in the access to information using equipments and devices with access to the web, namely to geographic information themes, has provided the possibility to amplify the knowledge of places and of the world. But it is not only the access to "global" information that enables significant progress within the knowledge of space and its dynamics, it is also the way people communicate that has been suffering a deep change by means of the increased communication periods of time through systems that are technologically mediated.

Assuming that immediate communication and access to information changes how people perceive, live and become involved in the geographical space, then the aim of this article is to contribute to the debate on the relevance of introducing information and communication technologies (ICT) into geographical education and teaching. With this in mind, this article takes into consideration only a small, yet important, part of the matters involved in issues of geographical education development - the training of Geography teachers. The territory under observation is Portugal, but the focus is also put on a representative sample of Geography teachers, which has been selected from those at an early stage of training. The contribution of this article to the debate on the relevance of ICT for geographical teaching and education is, therefore, the cross-analysis of syllabi taught at Portuguese universities during the professionalisation stage and the topics chosen by students (future professionals) in order to prepare the end of course report. In this way, we discussed the need to introduce changes in the professionalisation of Geography teachers, leading to the presentation of a new curricular structure for the $2^{\text {nd }}$ cycle of the teaching of Geography for 2015/16.

This approach is based on similar studies developed by authors such as Butt (2015); Schee, Lidstone and Brooks (2014); González, Donert (2014); Schemeinck and Lidstone (2014); William (2012); Kidman and Papadimitriou (2012); Stoltman (2012); Lidstone and Williams (2006); and Gerber (2003).

From the methodological point of view, Kidman and Papadmitriou (2012) conducted a content analysis of 18 years of the International Research in Geographical and Environmental Education, with the aim to analyse the research directions within this knowledge field. The authors have looked into the contents of 526 articles published between 1992 and 2009 and registered the importance given to some issues, such as: "values, attitudes and student's choice"; "teaching and teacher education"; "syllabus and textbooks, curriculum, assessment", and "inquiry, problem solving, knowledge and understanding". Quite the opposite, the "tools, GIS and computers"; "culture, language and political" or "spatial intelligence and mapping" were not as visible in the research trends (Kidman and Papadimitriou, 2012, p. 5). In fact, as stated by the authors, the changes that took place in the early $21^{\text {st }}$ s century seem to have been decisive for triggering the change in research focus: “... the launching of Google Earth in 
June 2005 may have also boosted the renewed interest in education in/about/with GIS and geospatial technologies. However, it is interesting to observe that these technologies seem to have replaced the theme 'visual and spatial intelligence, mapping', which had a peak in 1998-1999 and then declined" (Kidman and Papadimitriou, 2012, p. 9). However, topics related to the development of spatial intelligence, mapping and experimental teaching based on the transfer of knowledge are still relevant, with emphasis on the emergent introduction of computers, GIS and tools related to geographical teaching and education (Kidman and Papadimitriou, 2012, p.9).

Authors Sinton and Lund (2006) refer to the interest of geographical information systems that has extended to other scientific areas such as History, Anthropology and Economics, and that since the 1990s some of the articles published consider the introduction of GIS as a revolution. In this regard, authors such as Mann (1997) question whether science and research are ready for this revolution.

Today, the use of GIS as a teaching tool has been applied to all levels of education. Its implementation, however, is still at an early stage, which can be easily identified in the many documents reporting on didactic experiences (Stinton, 2009; Yaolin, 2014; Demirci, Kilar, 2014).

With identical purposes, Stoltman (2012) has presented the results of his research at the 2012 Congress of the International Geographical Union (IGU) in Cologne and at the 2012 Symposium of the Commission on Geography Education (IGU-CGE) in Freiburg, explaining that "the evidence suggests that traditional interests of geography educators continue to prevail in the categories such as pedagogy and teacher preparation. Interest in the use of geospatial technologies is on the increase, as are the topics of spatial thinking and sustainable development" (Stoltman, 2012, p. 17). The author explains that a great part of the communications have focused on themes such as "Pedagogy", "Teacher Preparation", "Technology in Teaching" and "Knowledge and Assessment", and, with less emphasis, on the themes related to the "Standards in Geography", "Textbooks" and "Philosophy of Teaching". In Cologne, the focus was put on "Education for Sustainable Development and Global Learning", "Examples of Best Practice in Geography Education and Teacher Preparation", "Spatial Thinking", "Standards, Concepts and Experience", and the "State of the Art in Geography Education", as well as on a smaller number of themes like "Higher Education", "Innovative Learning, New and Traditional Media", and "Preconceptions in Geography and Geography Education" (Stoltman, 2012, p. 19, p. 21).

Baker et al. (2012) identified six milestones (publications between 1990 and 2012) in the advancement of the use of GIS in teaching: 1990 "National Centre for Geographic Information and Analysis GIS Core Curriculum" (structure of the first GIS courses); 1994 - "First National Conference on the Educational Applications of GIS (EdGIS): Conference Report" (60 teachers express their concerns about teaching with and without using GIS as a tool); 2003 - "Special issue of the Journal of Geography Research on GIS in education" (reference to relevant work on 
GIS and education, but thought was also given to what could still be done); 2006 - "Learning to Think Spatially: the Incorporation of Geographic Information Science across the K-12 Curriculum" (in particular the recommendation about introducing "spatial thinking" and GIS in several disciplines at various levels of the education system); 2008 - "Digital Geography: Geospatial Technologies in the Social Studies Classroom" (examples of how the GIS can be used in secondary and university education); 2012 - "International Perspectives on Teaching and Learning with GIS in Secondary School" (successful outcomes in applying GIS as a teaching tool in 33 countries).

In the case of the teaching of Geography in Portugal, there are still only a few authors concerned with these issues, both in terms of methodology and scientific reflection. However, some steps have been made towards integrating new geographical information technologies to develop the spatialisation of individuals in all levels of education - note that in 2014, following the government's recommendation to include orientation and referencing technologies, the $7^{\text {th }}$ grade Geography textbooks were again subject to accreditation. Although it was optional, all authors and publishers decided to include this alteration in the textbooks. This is, in fact, one of the most recent recommendations that we know that is designed for providing space-based technologies in the teaching of Geography, intended for the $7^{\text {th }}$ grade of basic Education in the Portuguese education system, which is divided into four levels (Ministério da Educação, 2007): Pre-school education (attendance is optional) for children aged 3 to 5; Basic Education (attendance is mandatory), lasting 9 years (divided into 3 cycles: $1^{\text {st }}$ cycle lasts 4 years and is for children aged 6 to $10 ; 2^{\text {nd }}$ Cycle lasts 2 years and is for children aged 10 to $12 ; 3^{\text {rd }}$ Cycle lasts 3 years and is for students aged 12 to 15); Secondary Education has a duration of 3 years and can be directed to a profession or to university studies; Higher Education is governed by the principles of the Bologna process and, as such, consists of 3 years of Licenciatura [undergraduate degree] and 2 years of Masters.

Among agents and actors responsible for the necessary adjustments, in order to use ICT in teaching, as already mentioned, teacher training is a key factor in the entire process. In Portugal, after a long period of experience in the education of Portuguese Geography teachers, based on Decree-Law No. 74/2006, 24 $4^{\text {th }}$ of March (changed by Decree-Laws No. $107 / 2008,25^{\text {th }}$ of June, and No. 230/2009, $14^{\text {th }}$ of September), and the specificity assigned to it by reference number 11 of the Annex of the Decree-Law No. 43/2007, 22 $2^{\text {nd }}$ of February, the current model of initial education of Geography teachers is introduced, by adding to it the professionalisation in History. After seven years, Decree-Law No. 79/2014 has once again separated these scientific areas, and the new study plan for the "Master's Degree in Geography Teaching" of the University of Porto was approved, to begin in the academic year 2015/16.

Inspired by one of the basic principles of the Declaration of Rome on the Geographical Education in Europe (2013), the $4^{\text {th }}$ Congress of the 
Association of Geographical Societies in Europe (EUGEO), according to which "an appropriate use of geospatial data and technologies is necessary to help analyse and address problems related to water, climate, energy, sustainable development, natural hazards, globalisation and urban growth", the new study plan for the education of Geography teachers results from a profound self-assessment reflection. In relation to this process, what we have here is a cross-assessment of study plans, thematic choices made by the future teachers of Geography in their internship reports (academic dissertations defended in public exams) and international scientific production.

\section{MATERIALS AND METHODS}

In addition to the required review of literature, our work is based on:

- 151 internship reports part of the curricular unit Introduction to Professional Practice (from 2010 to 2015), published in the open repositories of seven Portuguese universities (five public and two private universities);

- the study plans of the $2^{\text {nd }}$ cycles of Teaching of History and Geography taught at those universities;

- the works by Kidman and Papadimitriou (2012) and Stoltman (2012).

The work methodology consisted of an exercise to process the contents of the internship reports, based on title, keywords and abstracts. Having repeated the exercise with the curricular units of each study plan, we then cross-analysed the contents (using descriptive statistics and proximity assessment by analysing graphics in NodeXL) and built the thematic categories.

Finally, we processed the new study plan for the $2^{\text {nd }}$ cycle in the teaching of Geography, taking into consideration the most relevant international topics to understand how they related to the research trends in the teaching of Geography.

\section{RESULTS AND DISCUSSION}

The analysis of the contents of 151 internship reports (academic dissertations) shows primarily a greater representativity of the University of Porto, which is explained by a more regular edition of the study cycle over the five years under analysis (Figure 1 ). 
ROMANIAN REVIEW OF GEOGRAPHICAL EDUCATION, Volume IV, Number 2, August 2015

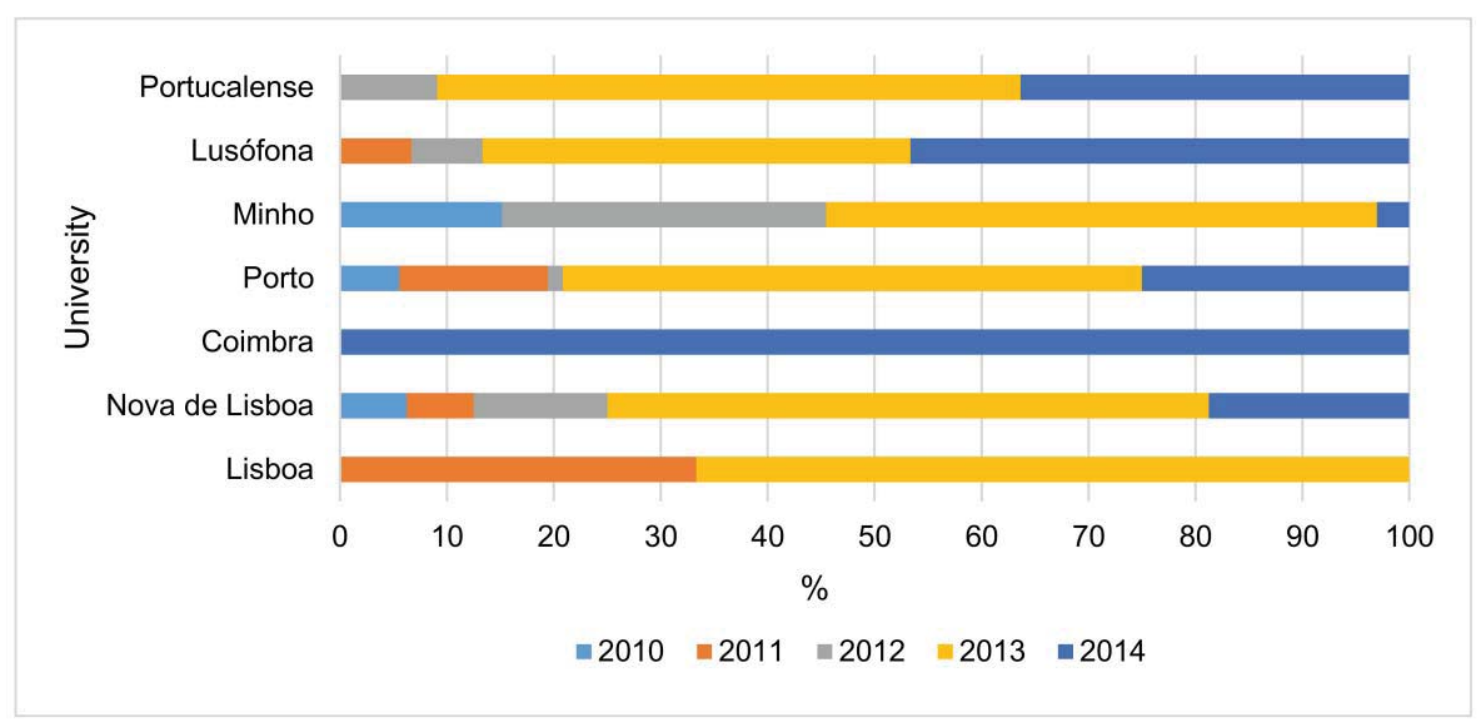

Fig. 1. Percentage of dissertations per year and per university

In fact, unlike the University of Coimbra, from which it was only possible to obtain information for 2014, both the University of Porto and Nova University of Lisbon (Nova de Lisboa) have a reasonable number of reports. These differences are explained by the excellence of the open repository of the University of Porto at national level and, because we are assessing only the research trends in the teaching of Geography in Portugal, this cannot be considered as a deviation factor in the final results.

From the content analysis of the internship reports it was possible to identify the major issues on the geographical education and teaching. For this end, we followed a methodology proposed by Kidman and Papadimitriou, which, as they explain, is based on the works of Chang, Chang and Tseng (2010): "... instead of matching each published item with a pre-set topic structure, the topics, themes and clusters developed inductively as they emerged from the entire corpus [...] Each published item was categorised into topics, and topics were later grouped into themes. Clusters of themes then emerged. It needs to be acknowledged that there is an unavoidable level of imprecision associated with this classification exercise" (Kidman and Papadimitriou, 2012, p. 4). So, at this stage of work we have identified 166 topics that were later grouped into 28 themes (Figure 2). 

Volume IV, Number 2, August 2015

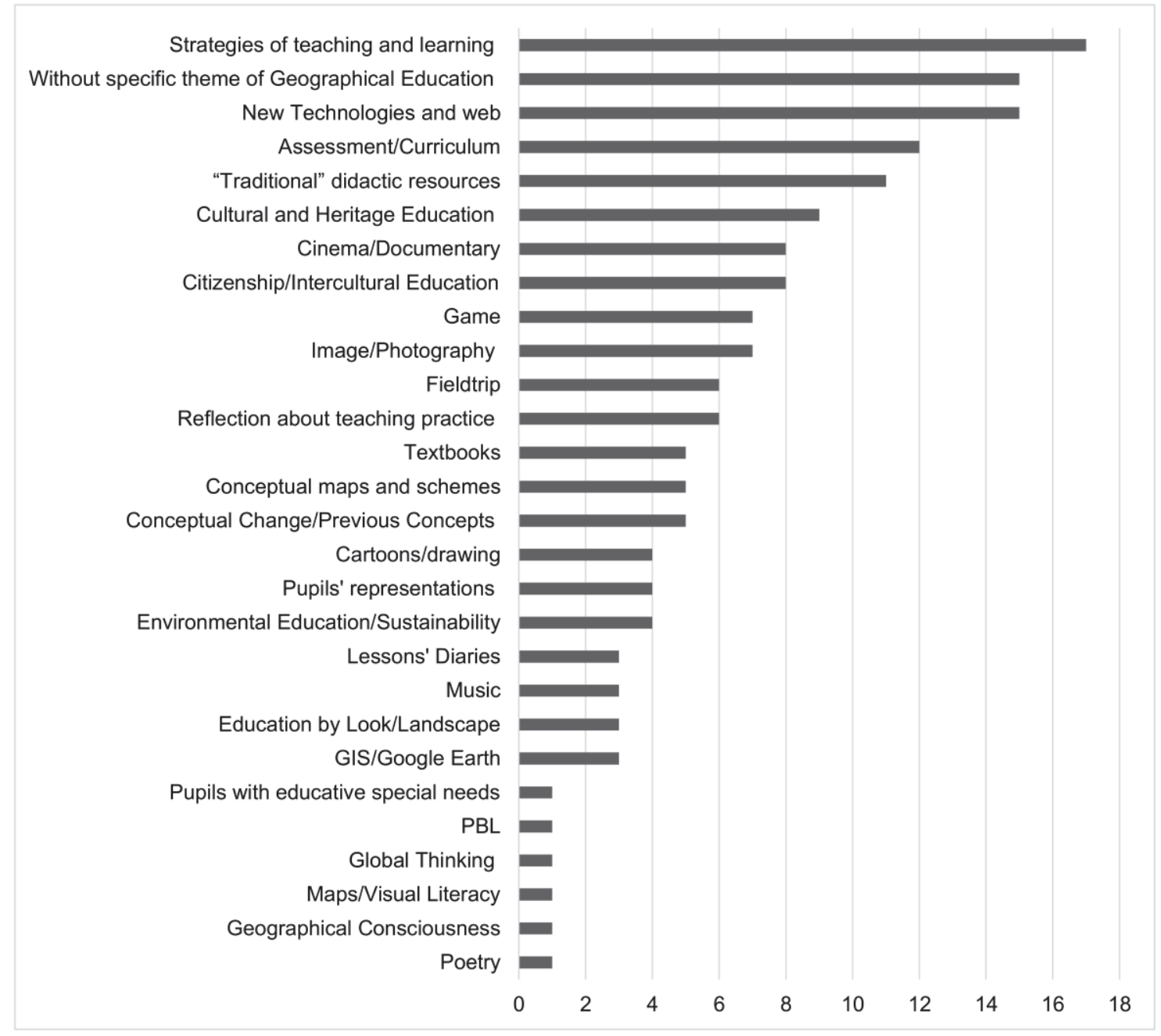

Fig. 2. Number of references of each identified issue about Geographical Education

Here, issues like Strategies of Teaching and Learning, New Technologies and Web, and Assessment/Curriculum are highlighted. The less highlighted issues include Poetry, Geographical Consciousness, Maps/Visual Literacy, Global Thinking, Problem Based Learning (PBL) and Pupils with Educational Special Needs. We underline that 15 dissertations did not address geographical education issues, which explains the fact of being possible to develop a professional field of work only in one of the areas of the Master's Degree - Geography or History -, such value corresponding to the professionalisation works in History.

Taking as reference themes that can be internationally compared, the previous subcategories were grouped into six categories (Figure 3), which results in a distribution that clarifies the options in the approach of the most traditional themes within teacher education. The themes Curriculum, Assessment and Teaching Methodologies and "Traditional" Didactic Resources amounted to $81 \%$ of the references, and the category GIS and New Technologies had only $11 \%$. 


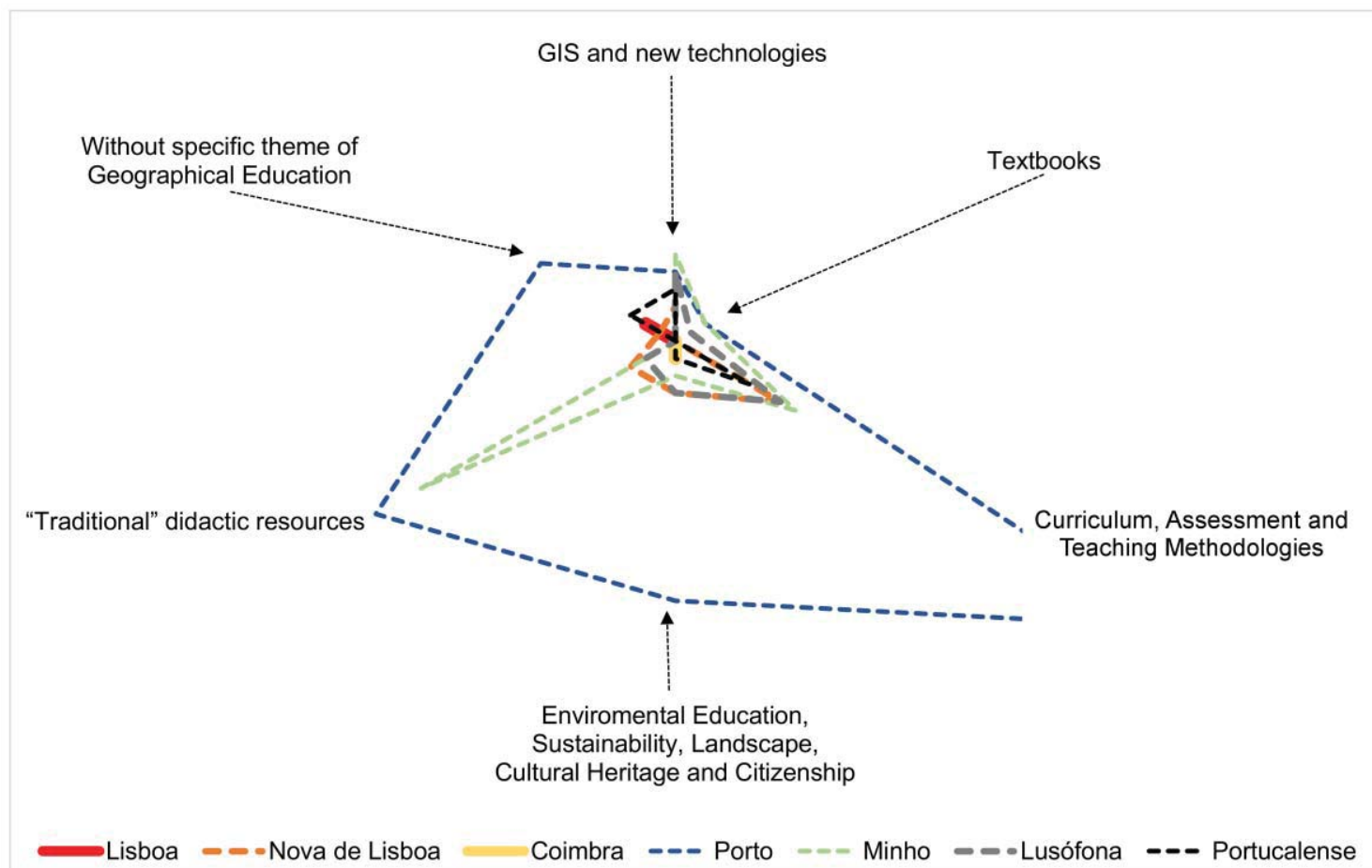

Fig. 3. Issues about Geographical Education in master dissertations of History and Geography Teaching in Portugal (2010-2014)

Still by means of using the categorisation of the themes addressed in the dissertations from those different universities, we realised that there were issues that were common. To accomplish this analysis, we realised a chart, where the information is organised into five categories represented by a colour, and each (circular or square) node symbolized a theme or university, the size of which varied according to the various connections it presented. The theme approached by each university was represented by connections, and its intensity varied depending on the number of dissertations that addressed the theme in question. Given this representation, one may see in Figure 4 that themes such as "new technologies and web" were addressed in dissertations from five universities and that showed the presence of sensitivity towards these issues among the majority. On the other hand, it is also possible to ascertain that in institutions, such as the University of Porto, the most common themes were the ones related to didactics, although we noticed recent efforts regarding other themes, as it was the case of "cinema/documentary". In the University of Minho, we noticed that themes were more diffuse, so none exceled in particular. 


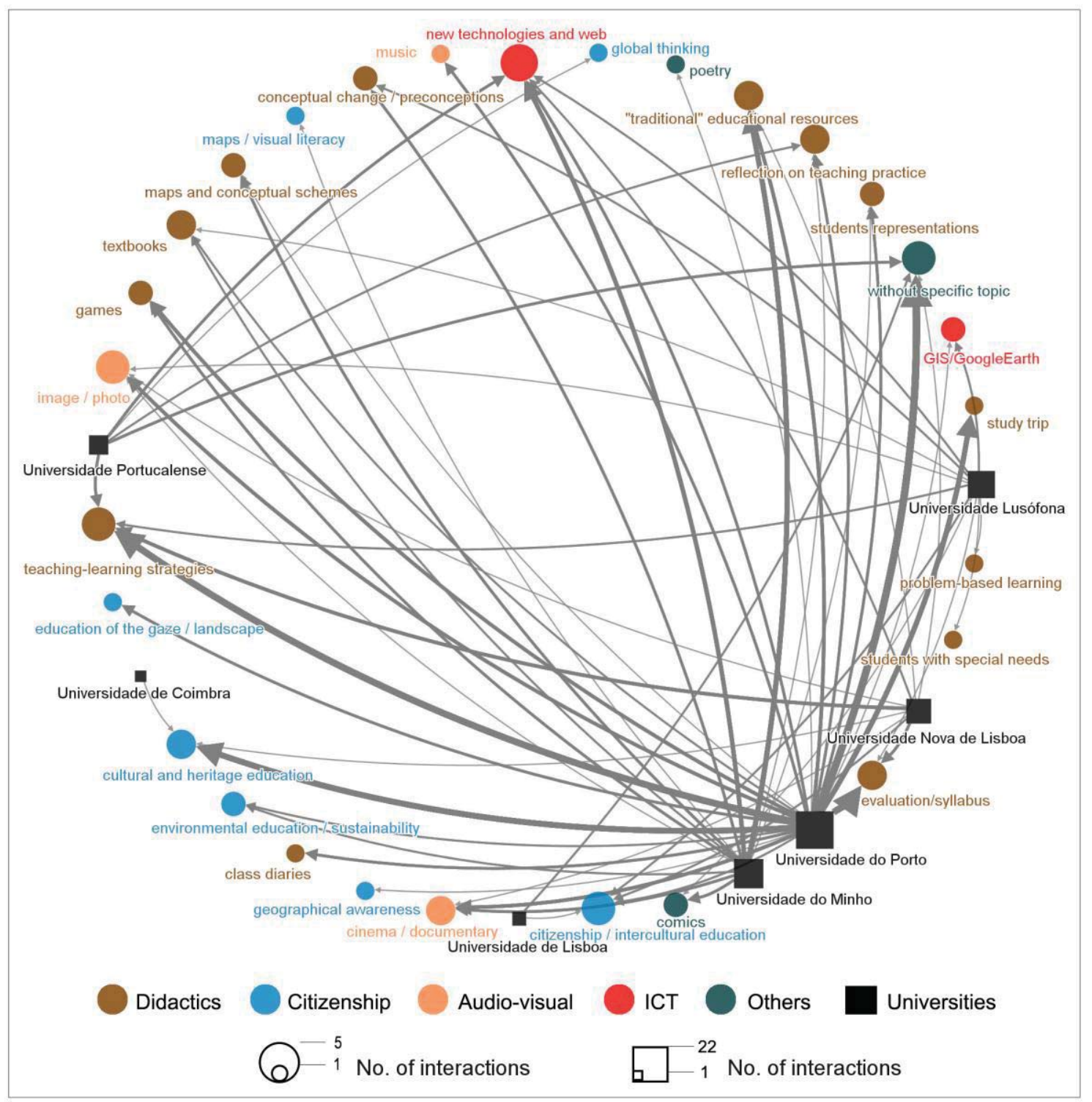

Fig. 4. Relationship between subjects of dissertations and universities

It also should be noted that although the emphasis is placed on themes around the didactics of Geography, we would expect more development in the field of ICT.

While seeking an explanation for these results, we crossed this reading with the current study plans of each university. It can be seen that because of the limitations set by Decree-Law No. 43/2007 (prior to the current legal framework), and although there was little room left for the distribution of ECTS in the fields of General Educational Training (FEG), Teaching Training (FAD), Specific Didactics (DE) and Introduction to Professional Practice (IPP), some universities included the educational technologies in their study plans, split between the DE and FEG. 
Interestingly, these are the universities that have a reasonable number of dissertations outside the more traditional themes, paying more attention to issues related to technologies in education, as is the case of the University of Minho, with the highest number of references to "GIS and new technologies".

The comparison of curricular plans for these study cycles in the teaching of Geography, organised according to the training areas that allow universities more flexibility in terms of their structure (table 1 ) shows that the themes of psychology, curriculum and didactics are stable. On the other hand, the more practical course units, whether related to application, methodologies or approaches to ICT, are different in the study plans of the higher education institutions under analysis.

Table 1. Comparison between Syllabi

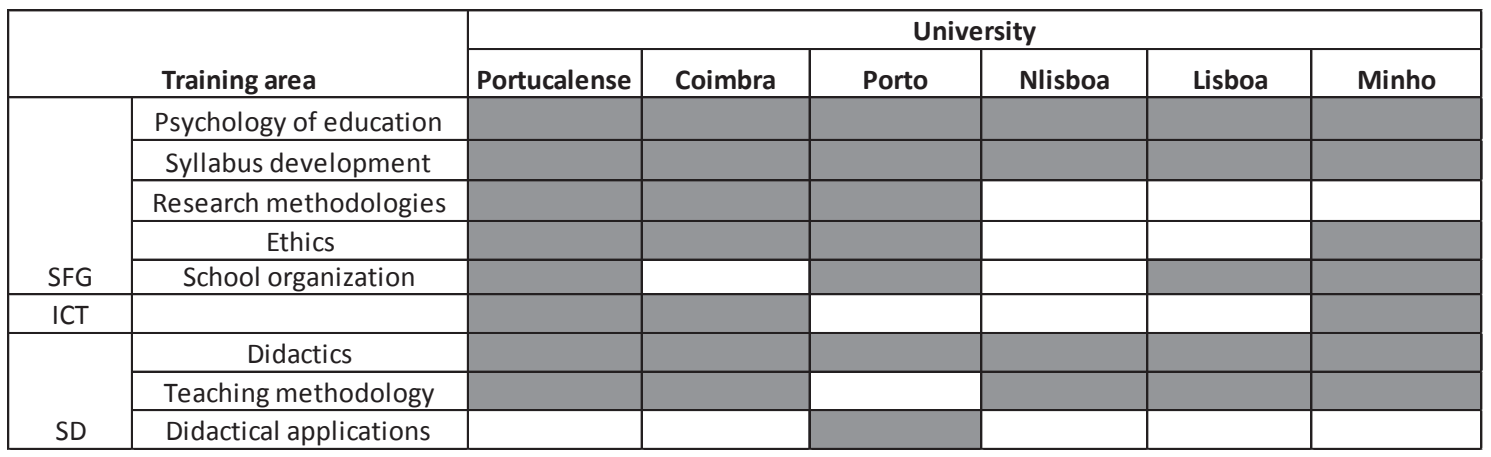

If we cross-analyse the information in Figures 4 and 5, we can easily realise that the curricular structure encourages the academic production of the future teachers of Geography, in other words, considering that the choice of themes is free, that same choice is strongly related with the training acquired in the curricular units comprised by the study plan of each university.

We also underline that the category that is a reference in all universities is "Environmental Education, Sustainability, Landscape, Cultural Heritage and Citizenship", and on the opposite side there are themes associated with "Textbooks". This observation is in line with the emerging issues within global social and economic development, including environment and preservation, memory and identity, and with the projects carried out in schools where students take their internship. Moreover, we noticed the increasing role of technological mediation and teaching/learning "cloud spaces" in most schools where the availability of information tends to be greater, which is a sign of change in behaviour towards adhering to the new information and communication technologies in many circles of sociability and communication, teaching and education included. 


\begin{tabular}{|c|c|}
\hline $\begin{array}{c}\text { Kidman and } \\
\text { Papadimitriou (2012) }\end{array}$ & $\begin{array}{c}\text { Assessment } \\
\text { Understanding Cultural } \\
\text { Political Studentigence } \\
\text { computers Student } \\
\text { Syllabus Inquiry Tools } \\
\text { Teaching } \begin{array}{c}\text { Language } \\
\text { Visual }\end{array} \text { Choice } \\
\text { Values Spatial Knowledghere } \\
\text { Curriculum Problem Education } \\
\text { Solving Attitudes }\end{array}$ \\
\hline Stoltman (2012) & $\begin{array}{l}\text { Preparation } \\
\text { Experience Geographical } \\
\text { Art Standards } \\
\text { Practice Education } \\
\text { Examples Philosophy Media } \\
\text { Global Sustainable Pedagogy } \\
\text { Assessment Best Concepts } \\
\text { Higher Textbooks Spatial } \\
\text { Technology Teaching } \\
\text { State Learning Thinking } \\
\text { Preconceptions New Teacher } \\
\text { Innovative Knowledge } \\
\text { Development Traditional } \\
\text { Geography }\end{array}$ \\
\hline $\begin{array}{l}\text { Research in Portugal } \\
(2015)\end{array}$ & $\begin{array}{c}\text { Curriculum } \\
\text { didactic Teaching } \\
\text { technologies Textbooks } \\
\text { Heritage new Gs resources } \\
\text { Environmental Traditional } \\
\text { Education Methodologies } \\
\text { Assessment Cultural } \\
\text { Landscape Sustainability } \\
\text { Citizenship }\end{array}$ \\
\hline
\end{tabular}

Fig. 5. The more and the less relevant issues in Geographical Education in the research of Kidman and Papadimitriou (2012), Stoltman (2012) and in Portuguese present research (2015)

Finally, we cross-analysed the previous readings (research themes on the teaching of Geography in Portugal, 2015) with the most relevant themes on geographical education referred to in Kidman and Papadimitriou and Stoltman works, both from 2012 (Figure 5).

The methodology used consisted in counting the words used in a Word-cloud (where the dimension of those used more frequently was greater), to highlight that (1) education and assessment was considered by all as the key themes more often used in research works; (2) the curriculum 
was highlighted in the works pinpointed by Kidman and Papadimitriou in Portugal; (3) knowledge was, according to both authors, particularly important, but not in the Portuguese research; (4) Kidman and Papadimitriou identified textbooks as a frequent approach in the analysis carried out.

Words with a smaller dimension in world-clouds reflected less scientific production. At this point, the embryonic phase of the development of new trends in geography teaching and education is confirmed for matters such as the use of ICT, which are often presented as opposed to more traditional perspectives, as well as the relevance of its use and approach in higher education, as stressed by Stoltman.

This analysis allowed producing a reflection on the proposal of a new study plan for the $2^{\text {nd }}$ cycle in the teaching of Geography, the result of which is the confirmation that we need to update teacher training so that it can be more open to current issues related to Geography education and teaching. To put it differently, higher education study plans too focused on closed approaches to the concepts of didactics, assessment or, among others, the curriculum, are unlikely to raise the awareness of future teachers to the need to teach using the technologies available to the young students at younger and younger ages.

For these reasons, we took the opportunity of this debate to submit a proposal for the new Master in the Teaching of Geography in the University of Porto, which seeks to promote the quality of initial teacher training, in particular in the specific area of didactics. There is no point in planning lessons if the teacher does not use the resources and/or communication channels that are stimulating and even more perceptible to students.

In the new proposed plan for teacher training, which was already approved by the Assessment and Accreditation Agency for Higher Education, themes such as ICT and other themes essential for the development of teachers' awareness towards reading and comprehending spatial and land-based events are part of the syllabi of the following courses: Didactic Applications in Geography; Geography Didactics and Geographical Teaching and Education, and ICT and Geography Teaching, the latter with double the credits of the others.

The aim, therefore, is to provide knowledge and skills to new Geography teachers, who did their professionalisation at the University of Porto, so as to enable them to meet the challenges of Geography teaching in the $21^{\text {st }}$ century, as well as articulate and adjust teacher education to the major trends in the research within geographical education at an international level. The design of the new study plan for Geography teacher education and training offered by the University of Porto fits the current recommendations and international research works, and aims to provide graduates not only with Geography teaching skills within basic and secondary education, but also with the knowledge that will allow them to mobilise updated research, and even new readings/outcomes based on 
internship reports. Future teachers will have to be prepared for rapidly changing educational contexts - which is particularly relevant for geographers, as the use of new technologies has immediate effects on the interaction and interpretation of territorial and/or geographical-based events.

\section{CONCLUSIONS}

We can conclude that today the use of new technologies and the GIS still have a secondary role in teacher education and training. It is up to the institutions providing teacher education and training to create the conditions for their development through the integration of international research networks, adequacy of study plans, creation of new course units characteristic for ICT, and hiring new teachers in the field of technologies.

In this sense, this research is extremely relevant in the national framework, since it is still at an early development stage, and also in the international framework, as it contributes to the reflection on these matters. This analysis and discussion of results was crucial for the necessary alterations in the study plan of the Master's Degree in Geography Teaching in the University of Porto. At an international level, it provides information to researchers from various countries on the themes dealt with within the Teaching of Geography in Portugal, based on the information provided by teachers undergoing initial training. It also contains the views considered in the reflection prior to the curricular change in Geography teaching at the University of Porto, particularly, by way of conclusion:

1. As agents of geographical education, during training, teachers must be provided with the knowledge and practices needed to facilitate teaching-learning. This inevitably involves the development of advanced competences to adapt to a rapidly changing society, where space and time (concepts inherent to Geography) are greatly transformed by every technological advancement.

2. The training and sensitivity of these education professionals are strongly anchored in education/training and university professionalisation, so it is up to higher education to take the first step towards change.

3. Since a general education background and specific didactics are important, because it is essential to understand the past and the processes/contexts of teaching and learning, this is where we must develop the notion of living in a society in which the means and modes of communication are mediated by technology.

4. The investment in ICT in the area of teacher education and training in the didactics of Geography is believed to be the lever that is required to implement the necessary changes in both research and in the professional practices of future Geography teachers. 
The results of this first exercise raise much interest about teacher education and training and research interests in the teaching of Geography in other countries. In this sense, it may be interesting to reflect on this at an international level so that we can assess, by comparison, the results we have shown here. This research would allow us to learn about the "good practices" and "good models" of the various countries, to promote the quality of this education/training through the sharing of experiences. To conclude, this joint research could lead to the creation of a European Master (degree and title given by several universities) in Geographical Education. The challenge is on!

\section{Acknowledgement}

"This work was funded by National Funds through FCT - Foundation for Science and Technology within the project UID/HIS/04059/2013"

\section{References}

Baker, T., Kerski, J., Huynh, N. T., Viehrig, K., \& Bednarz, S. (2012). Call for an Agenda and Center for GIS Education Research. Review of International Geographical Education Online, 2(3), pp. 254-288.

Butt, G. (ed.) (2015). MasterClass in Geography Education - Tranforming Teaching and Learning. London, Bloomsburry.

Dimirci, A., \& Kilar, A. (2013). Using Google Earth as an Educational Tool in Secondary School Geography Lessons. International Research in Geographical and Environmental Education, 22(4), pp. 277-290.

Gerber, R. (ed.) (2003). International Handbook on Geographical Education. Dordrecht, Kluwer Academic Publishers.

Kidman, G., \& Papadimitriou, F. (2012). Content Analysis of International Research in Geographical and Environmental Education: 18 Years of Academic Publishing. International Research in Geographical and Environmental Education, 21(1), pp. 3-10.

Lidstone, J., \& Williams, M. (ed.) (2006). Geographical Education in a Changing World: Past Experiences, Current Trends and Future Challenges. Dordrecht, Springer.

Mann, S. (1997). The GIS Revolution, Are We Ready for GeoComputation? Presentation made in GeoComputation 1997 \& SIRC 1997. University of Otago New Zealand 26-29 August 1997, pp. 15-23.

Ministério da Educação (2007). Educação e Formação em Portugal. Ed. Ministério da Educação. 


\section{ROMANIAN REVIEW OF GEOGRAPHICAL EDUCATION, Volume IV, Number 2, August 2015}

Schee, J., Lidstone, J., \& Brooks, C. (2014). Towards an International Approach for Geography Education. Geographia Polonica, 87(2), pp. 213-220.

Stinton, D. (2009). Roles for GIS within Higher Education. Journal of Geography in Higher Education, Vol. 33, Supplement 1, S7-S16, pp. 9-16.

Sinton, D., \& Lund, J. (2006). Understanding Place: GIS and Mapping across the Curriculum. Redlands, CA: ESRI Press.

Stoltman, J. (2012). Perspective on Geographical Education in the $21^{\text {st }}$ Century. Journal of Research and Didactics in Geography (J-READING), 0(1), pp. 17-24.

William, M. (2012). Towards a Framework for Research in Geographical Education. Anekumene, 3, pp. 52-70.

Schmeinck, D., \& Lidstone, J. (2014). Current Trends and Issues in Geographical Education. Standards and Research in Geographical Education: Current Trends and International Issues. Berlin, Mensch und Buch Verlag, pp. 5-16.

Yaolin, L., \& Yuanchun, S. (2014). Analysis of GIS Higher Education in China. International Archives of the Photogrammetry, Remote Sensing \& Spatial Information Sciences, Vol. 40-6, pp. 59-66. 